study on the System for Checking and Evaluatina Military and Policicai orficers

\author{
Sun Hongcai, Tian Ping, Wang zhongxin \\ and Gong Museng
}

Introduction:

Since the Third Plenary Session of the 11th Party Central Committee ended, reform, as one of the significant strateqic decisions for the socialistic modernization. has been the main work of the Party. Quickening and deepening reformation was also the central topic of the 13th National Congress of the Party. The reformation of politic system will surely include and push forward the reformation in officer system.

The reformation in officer system consists in many aspects, and it is of various hierarchies. One of its important task is to gradually complete a whole set of scientific and realistic system for administering officers, and the key link in the reformation of administrative system is to reform the checking methods for officers.

We used to check officers in a traditional qualitative checking method, that is, talking with the checked officer and the comrades around him; calling together some people to have informal discussions: checking his records and getting information of the checked one of his past. present working attitude, and moral and vocational level, etc. We then qualitatively analyzed all of these information and gave evaluation and recommendation. The traditional checking method has played an active role in constructing the officer system in the army, and it has significant and realistic value even now. But, generally speaking, it is only a qualitative analysis for the individual officers being checked. so the method is to some degree limited. The shortcomings are: First. lack of quantitative analysis; second, emphasis on experimental impression and lack of scientific evaluation: third, emphasis on one's past and present working atticude but paying little attention to developina potentiality: and fourth, emphasis for group.

In order to make up for the deficiency of the traditional checking system for military and political oficers. we must begin quantitative study, so that we may judge and use an officer more suitably and urge officers to study hard, work actively and do their duty carefuliy. We can also raise the level of revolutionization and specialization of the officers and get more young officers with higher education. so as to meet the need of constructing a regularized revolution army.

Our main tasks of study are: how to use the theories in natural science and social science comprehensively to set up a relatively 
scientific quantitative model, how to fix a target system for the general quality the important military and political officers in the army, and how to use a new scientific method to determine the mutual restricting weighting of each hierarchy constructure.

I. The Target system for Checking and Evaluating the General Quality of the Military and Political officers

The general quality of the officers is an organic combination of many factors relating to and restricting each other. It's very complicated. Here we introduce the conception of hierarchy constructure, i.e. dividing the different rargets, and the relations controlled by or subordinated to them, of the general quality of officers into different hierarchies and showing the relations between the controlled targets to the main ones. After that, we can decompose and synthetize the target into an ordered hierarchy constructure according to the property of the relations among them.

Drawing a relatively reasonable system of targets is the presupposition and chief ground for checking and evaluating officers. As a part from reflecting the outline of the general quality of officers, the system must also be able to reflect the officer policy of the Party's and the fundamental principle of constructing the army in the new period.

Comrade Deng Xiaoping have given a series of important statements about constructing the officer system in the new period, the Central Military Commitree and General Political Department have given some policies and instructions about consrructing revolutionized and specialized younger officer groups with hicher level of knowledge, and the General Political Department have also given the checking System for officers in the People's Libration Army ( For soliciting opinions) and the criterion for checking officers. According to all of these and also the present condition in the army. we make the targets. We tried our best to combine the traditional system with the requirement in the new period and carry out the principle of considering both moral and vocational quality. so as to reflect the characteristics of checking system in the army.

wel divided the general quality of officers into three levels:

First. aim level: the general quality of the military and political officers $(\mathrm{z})$.

Second. principle level: it consists of five evaluating factors: moraliey ( $G$,'. capability ( $G$ '. industrv ( $G$ ' achievement $\left(\mathrm{G}_{4}\right)$ and health ( $\left.{ }_{5}\right)$.

Third. target level: it consists of 30 targets.

The principle of morality controls 8 taraets. and thev reflect 
mainly the officers condition in ideological morality and political character, etc.

The principle of capability controls 9 targets, and they chiefly check the basic quality of officers and their ability in doing their own vocational work and finishing certain tasks.

The principle of industry controls 5 rargets, and they check mainly the officers'working attitude and how much effort they put in study.

The 6 targets controlled by the principle of achievement mainly check how the plans for constructina the unit led by a checked officer have finished, how much he has carried out his duty and fulfilled the tasks of military training and political. vocational and cultural study.

The principle of health controls 2 targets. and they are used mainly for getting information of the physical condition of officers because the army is different from the locality. the former is strict to the age and physical condition of officers in service.

The system of checking and.evaluatina targets for the military and political officers is shown in Fig 1 .

In order to make the target system more generally used. we check the military officers and political officers using one system. Although they have different work, and the emphasis on checking them varies from one to the other. the requirements in checking are all the same. For example. when we evaluate an officer's morality, we must check his political consciousness. line of thought ideological morality and the enthusiasm in revolutionary cause, etc. The differences and emphases can be distinguished by coefficient of weighting.

II. Setting up the Function of the General quality of officers by Linear weighted sum Method

The targets for checking officers comprehensively form a complicated system. We set up a generalized objective function using linear weighted sum method in multiple target decision and combine all the factors. in the function oraanically, so the function can be used to quanlitity the ceneral quality of officers. We then use it to compare and evaluate officers quantitatively from the andle of ceneral auality. We call this generalized objective function as the function of officers' general quality. i.e.

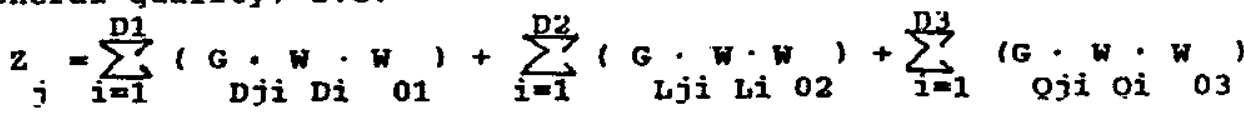

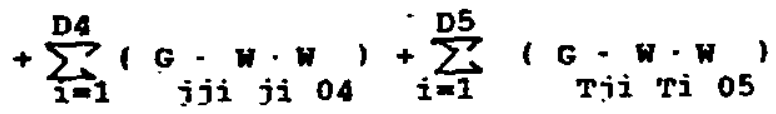




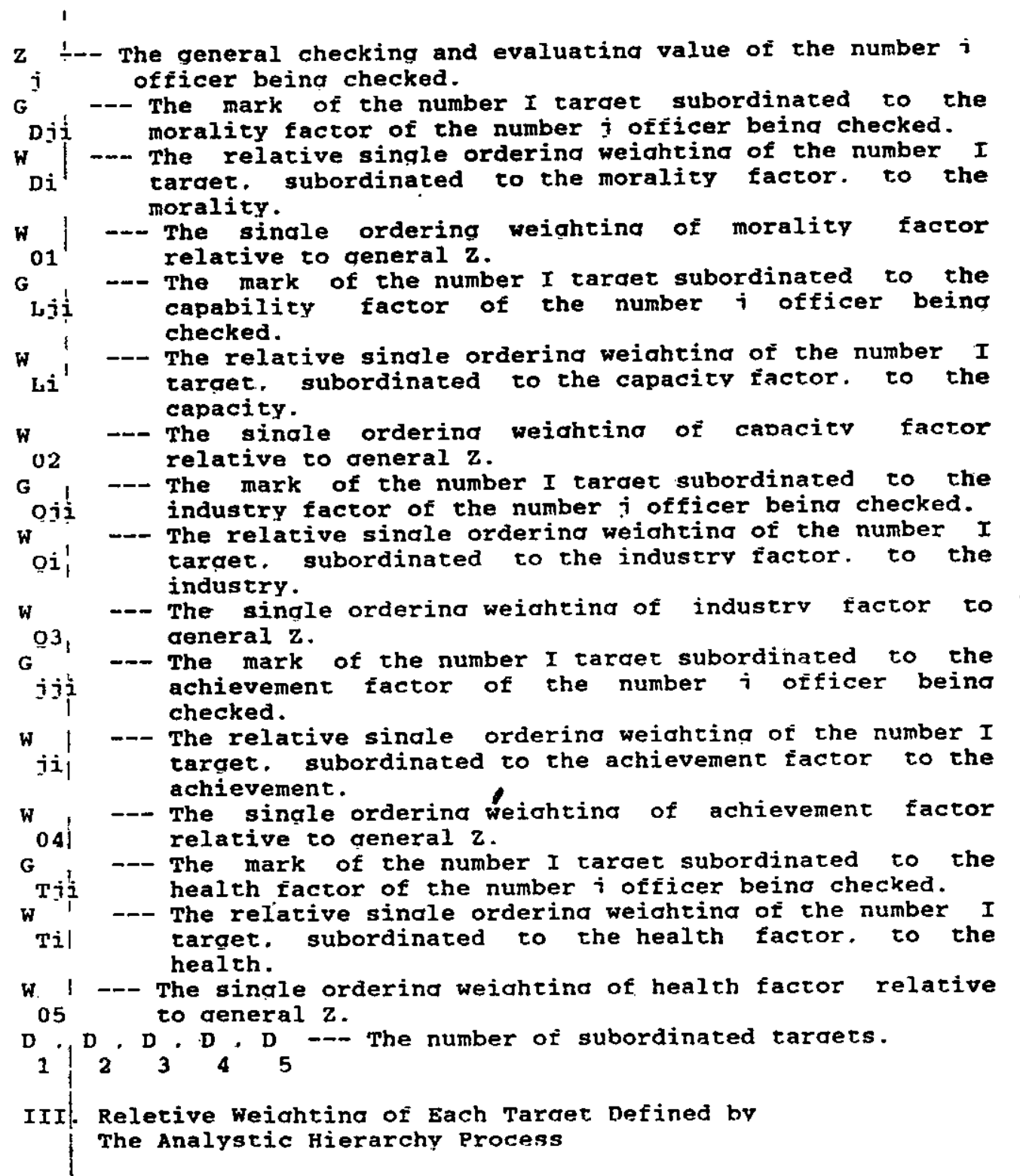

After the check and revaluation of cadres is set un with the hierarchy constructure, the main boint is definino the reletive weighting of each element. The correcrness and scjence of weightina will affect the result of the check. There are a lot of methods definina the weiahting. But throudh combarison. the Anaiytic Hierarchy Process is more suitable for human beina's thinking intuition. and it has hiah loaicalitv tlexibility. system and simplicity.

1 Military and Political officers Juddment Marrax and the 


\section{Calculation of Weiahtina}

When we make the judament matrix. we try to aive the rationality, exactness and credibility. Accordina to the requirements of different qualities of military and boliticil officers. we'll construct each of the military and political officers' iudoment matrixes.

We'd like to ask the comrades of cadre devartment and milirarv leaders to compare and iudge the relative $i m n o r t a n c e$ of each element of the two kinds of cadres and the following ivdament matrix and calculatina value.

1). The Judament Matrix in the Weiahtina of the Military cadre The Total Orderina Result of the whole constructure is:

\begin{tabular}{|c|c|c|c|c|c|c|c|c|}
\hline $\mathbf{z}$ & & G1 & G2 & G3 & F.4 & 6.5 & 1 & พ \\
\hline G1 & $i$ & 1 & 3 & 4 & 2 & 6 & 1 & 0.4201 \\
\hline G2 & 1 & $1 / 3$ & 1 & 2 & $1 / 2$ & 4 & 1 & 0.1638 \\
\hline G3 & $i$ & $1 / 4$ & $1 / 2$ & 1 & $1 / 3$ & 3 & $i$ & 0.1026 \\
\hline G4 & 1 & $1 / 2$ & 2 & 3 & 1 & 5 & $i$ & 0.2652 \\
\hline G5 & $i$ & $1 / 6$ & $1 / 4$ & $1 / 3$ & $1 / 5$ & 1 & 1 & 0.0484 \\
\hline & & $\lambda$ & 988 & & {$\left[\begin{array}{l}=0 \\
=1 \\
=0\end{array}\right.$} & & & \\
\hline
\end{tabular}

2). G1 - G1i Judament Matrix

\begin{tabular}{|c|c|c|c|c|c|c|c|c|c|c|}
\hline G1 & 1 & G11 & G12 & G13 & G14 & G15 & G16 & G17 & 618 & พ \\
\hline G11 & 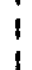 & 1 & 1 & 3 & 3 & 5 & 6 & 7 & 7 & 0.2847 \\
\hline G12 & $i$ & 1 & 1 & 3 & 3 & 5 & 6 & 7 & 7 & 0.2847 \\
\hline G13 & 1 & $1 / 3$ & $1 / 3$ & 1 & 1 & 3 & 4 & 5 & 6 & 0.1339 \\
\hline G14 & 1 & $1 / 3$ & $1 / 3$ & 1 & 1 & 3 & 4 & 5 & 6 & 0.1339 \\
\hline G15 & 1 & $1 / 5$ & $1 / 5$ & $1 / 3$ & $1 / 3$ & 1 & 2 & 3 & 3 & 0.0634 \\
\hline G16 & 1 & $1 / 6$ & $1 / 6$ & $1 / 4$ & $1 / 4$ & $1 / 2$ & 1 & 2 & 2 & 0.0425 \\
\hline G17 & $\begin{array}{l}1 \\
1\end{array}$ & $1 / 7$ & $1 / 7$ & $1 / 5$ & $1 / 5$ & $2 / 3$ & $1 / 2$ & 1 & 1 & 0.0284 \\
\hline G18 & 1 & $1 / 7$ & $1 / 7$ & $1 / 5$ & $1 / 5$ & $1 / 3$ & $1 / 2$ & 1 & 1 & 0.0284 \\
\hline
\end{tabular}




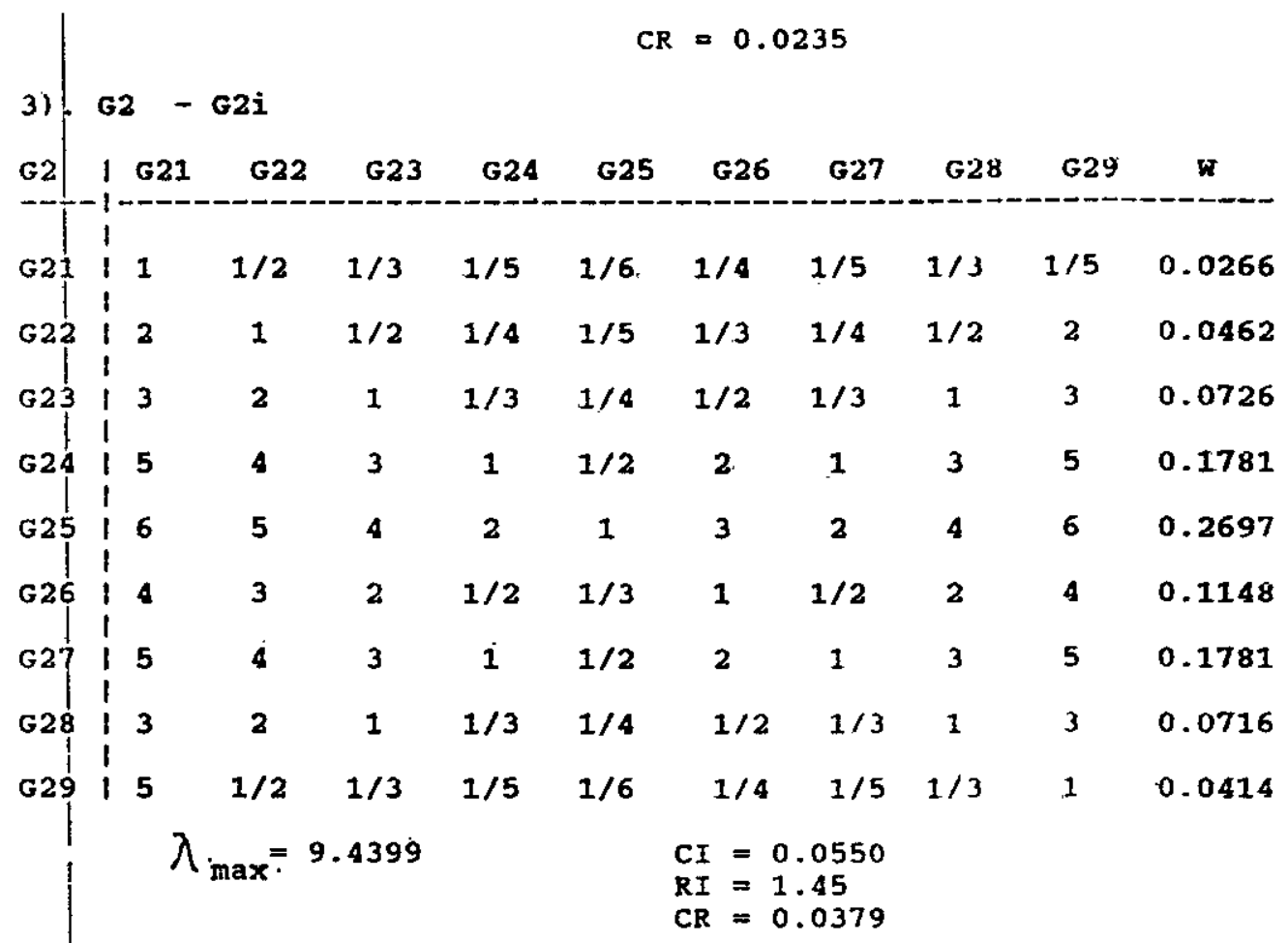

4) $G 3-G 3 i$

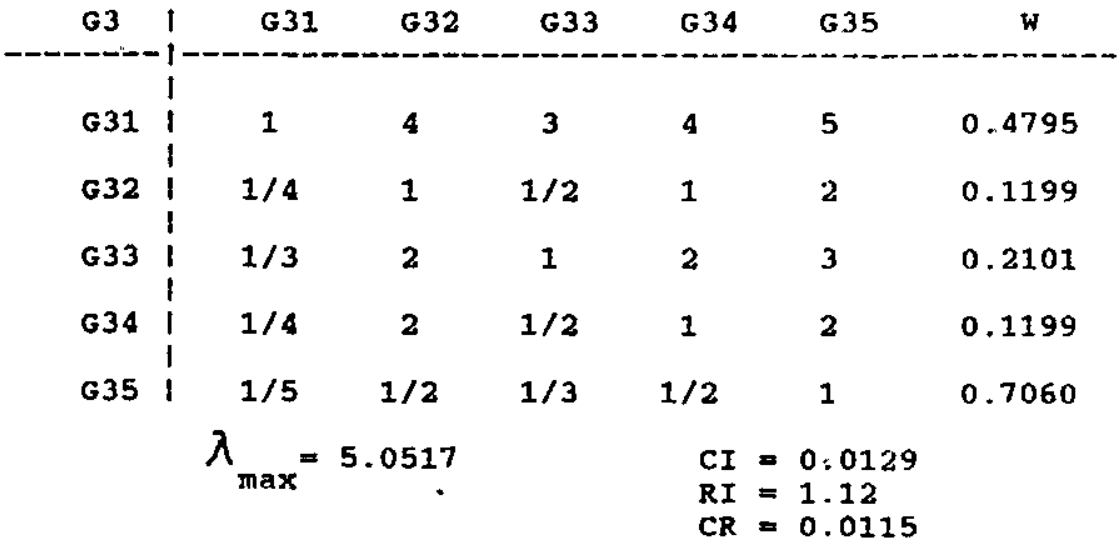


51 G4-G4i

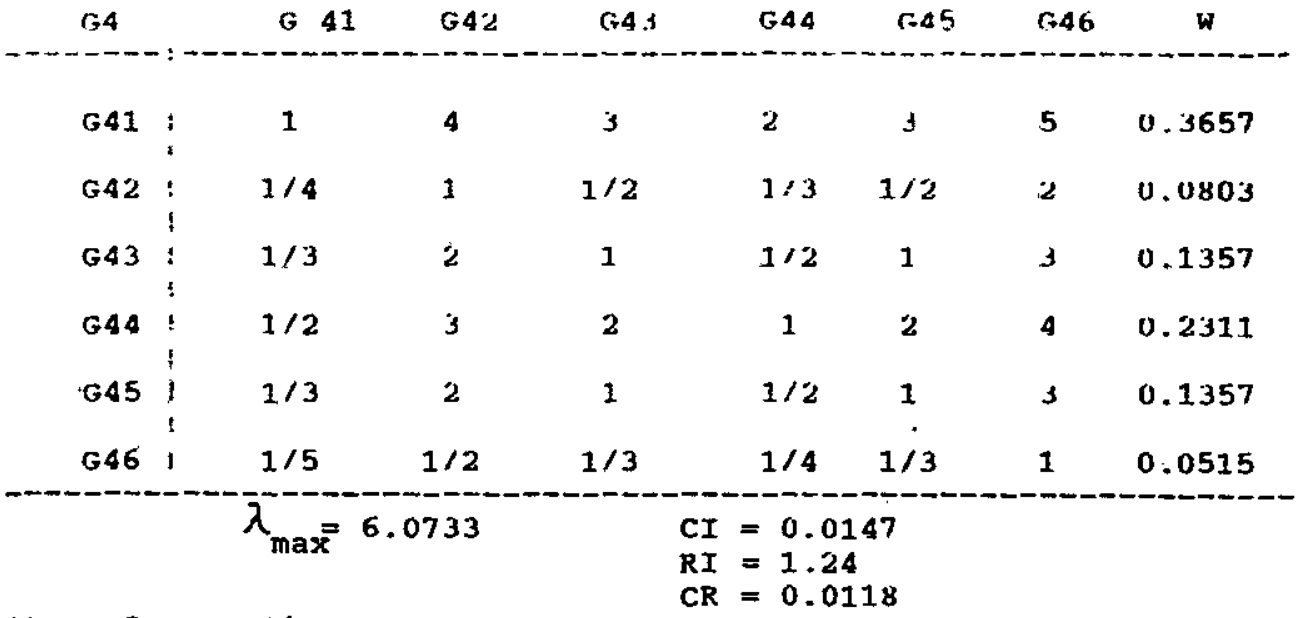

6). G5 - G5i

$\widehat{0}$

\begin{tabular}{c|cccc} 
G5 & G51 & G52 & W \\
\hdashline G51 & 1 & 1 & 2 & 0.6667 \\
G52 & 1 & $1 / 2$ & 1 & 0.3333 \\
\hline
\end{tabular}

$$
\begin{aligned}
\lambda_{\max } & =2.0000 \\
C I & =6.0000 \\
R I & =0.0000 \\
C R & =0.0000
\end{aligned}
$$

The Total Ordering Result of the whole Constructure:

$\begin{array}{llll}\text { W1 }=1.1196 & \text { W2 }=0.1196 & \text { W23 }=0.0970 & \text { W26 }=0.0613 \\ \text { W3 }=0.0563 & \text { W4 }=0.0563 & \text { W18 }=0.0492 & \text { W13 }=0.0442 \\ \text { W25 }=0.0360 & \text { W27 }=0.0360 & \text { W29 }=0.0322 & \text { W10 }=0.0292 \\ \text { W15 }=0.0292 & \text { W5 }=0.0267 & \text { W20 }=0.0215 & \text { W24 }=0.0213 \\ \text { W14 }=0.0188 & \text { W0 }=0.0179 & \text { W30 }=0.0161 & \text { W28 }=0.0137 \\ \text { W19 }=0.0123 & \text { W21 }=0.0123 & \text { W7 }=0.0120 & \text { W10 }=0.0076 \\ \text { W3 }=0.0120 & \text { W11 }=0.0119 & \text { W16 }=0.0119 & \\ \text { W22 }=0.0072 & \text { W17 }=0.0068 \text { W9W9 }=0.000046 & \end{array}$

The Consistent Target of the total ordering in the constructure:

$$
C I=0.0281 \quad R I=1.2735 \quad C R=0.0221
$$

To the qualities of a military and political cardre. revolution is kept on the first position in the five aspects. The other four are moralicy, capability, industriousness and system. Because the importance of morality is paid much more attention, its weiahtina is the hiohest $(0.4201)$. Next to the importance of the morality is the practical achievements of the cardre $(0.26652)$. The check of cardres and the practical achievements are important so that cardres can ho encouraced to do more practical thinos. and make more contributions. The third is capabilitv the fourth is industriousness. The fifth is system. 
Amona the eiqht tarqets in the morality principle. political consciousness and the line of thought are more important. Because military cardres must have communist consciousness and keep consistent with the central Committee in politics. The weiahtina of the two tarqets are both 0.2847 . The other two targets next to the above are qualities of thought and revolutionary devotion. As a military cardre, he must be honest. be open and aboveboard. be upriaht, act in justice, consciously devote to the defence cause of oux country. Iove the army, love his own work and can correctly deal with the relations between the revolutionarv and personal benefit.

Amona the 9 taraets in the capability orinciple. the cababilitv of organizing and commandina is much more important $10.2697 \mathrm{l}$. The military cardre must pocess hicher capability of oraanizina and commanding. We must have the sense of watchind overall situation and planning and arranging.

Hé must arrange each work suitably and command the army treely. so that the soldiers can fulfill the tasks of drillina everyday and finish the rasks of fiahtina durina the war. Next is the capability of judgina the decision, and the judaing capability of reforming. These two kinds of capabilities show not only the qualities that a military commander must have but also the requirments that he must fulfil the new tasks in new period of time.

Among the five rargets of the principle of industriousness. the most important one is the sense of responsibility. It j.s very important for military cadres to carry out resolutely the instructions of their commanders. work whole-heartedly and has the courage to bear duties. Next is the sense of service. That is to say military cardres must care about the construction of the army, serve for the army at basic level and oromptiv solve the problems of the army at basic level

Amona the six caraets in the orinciole of achievements the most improtant is doind duty , 03657 , A miljtarv radre must strictly do his duty of onst corrertily use has richr and creatively carry out his work

Between the 2 targers in the princinle of health the more improtant one is the ade $(0.6667)$. An army is a aroun with military equioment. Its tasks and the qualitv reruirements are about the appointment of younaer cadres.

2 The weightino Judament Matrıx of Politicar Carres

The calculated result of the weichtino is'. The Hierarchv rotal

ordering ).

$w 1=0.1114$

$\mathrm{WH}=0.0499$

$w_{1}=0.0339$

$\mathrm{w} 2=0.1114$

$\mathrm{W} 18=0.0429$

w23 $=0.0970$

$W 25=00360$

$w i=0.0207$

W1 $5=0.0339$

w29 $=0 \quad 0.322$

$w 12=0 \quad 0207$

$\mathrm{w16}=0020^{2}$

$w_{3}=0.0730$

$W 2.7=0 \quad 0369$

$w 20=00250$

Wh $=0$ itm 
$W 30=0.0161 \quad W 38=0.0137$

w21 $=0.0100 \quad W 17=0.0088$

$w 14=0.0124$

$w 7=0.0114$

W26 $=0.0613$ W5 $=0.0341$

W10 $=0.0077$

W22 = 0.0063

W8 $=0.0114 \quad$ W9 $=0.0049$

H24 $=0.0213$ W19 $=0.0164$

The Consistent Target of the Total orderina:

$$
C I=0.0229 \quad \mathrm{RI}=1.2735 \quad \mathrm{CR}=0.0180
$$

To the political officers. the relative proportions of morality. capability. industriousness. achievments and system at the second hierarchy are as same as those of military officers.

The relative weighting in each target of the morality principle

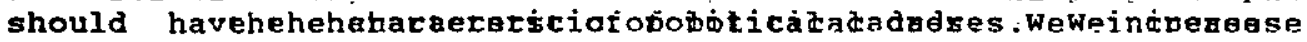
the weiahting of the morality of thought. If the political cadres are honest and just. don't abuse their riahts and keed word. the political prestige of the Party will be hiah.

Compared with the weiahting of military oroup. the relarive weiahtina in the nine taraets of the cababilitv orincisle is hiah in the level of bolicy. the creative abilitv of reform and the capabilitý of learnina about talents and using talents. Ift the political officer has a hiah level in theory and is familiar with the policies of the party. they can only control the situation and lead the army forward to the reformation. Meanwhile they often contact with person. so it is important if they can use intelligent talents.

In the weighting of the induscry princiole of political aroup. the relative weiahting of service is raised. others are similar to those of military officers.

In the achievements and health principles. the reletive weiahtina of each target is almost the same as that of military cadres.

IV. The Quantified Degree of Tarqets

The most important point in the quantity check of cadres is how to quantify the taraet system. We use numbers to express the evaluation to cadres. By the princiole of obscure mathematics. we combine the scale method with the subordinated markina method to increase the practice of AHP in the evaluation to the check of cadres. In order to conform people's habit subordinated dearee is used in the system of "hundred scores". It is devided by five levels: excellent. very aood. good. mediocre. and bad. Everv level is again devided inco three barts: betrer than averade. averace and below averace. Every level has a markina srandard. Accordina to this standard. a cadre can be evaluated and checked in quality right and obiectively. The markina standard of the check is shown in table $I$ - table $v$.

On the level of "excellent" the markina: (97-99). (94-96), (9093).

On the level of "very cood": $(87-89),(84-86),(80-83)$.

On the level of "rood" : (77-79). (74-76), (79-73).

on the level of "mediocre": (67-69). (64-66) (60-63). 
on the level of "bad" : the marks are below 60.

v) Adding Weightings ror Two Times

In order to heed the opinions from every aspects. the checked officers will be all-around devided into hiafer level equal level, and business debartment. Because of difrerent positions. different deqrees of understanding the checked officers and different andles of viewing questions, the evaluation to them can not be treated in equal level, and it must be aiven differont weightings, that is addina weiahtinos for two times. The judgement matrix of weighting and calculatina method is still expressed with AHP.

By adding weightings for two times. the function of the officer's whole qualitive is:

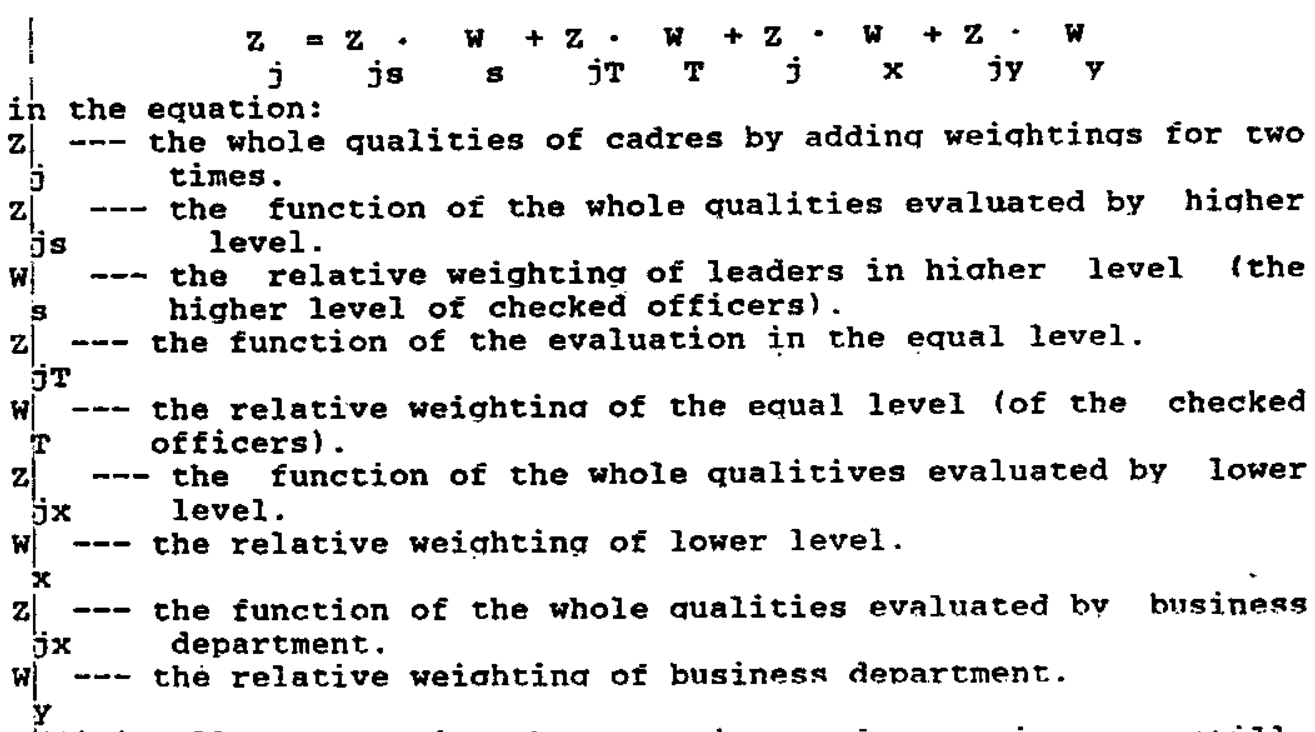

Additionally, concerning the convenience of combarison. we stil]

concern the standard marks of one person.

The method of addina weiahtinas for two times is used in the check of one person, and the effection of AHP in aroubs' decision is improved. Also the reliability of the result in the check and evaulation is raised.

The Judgement Matrix of Adding Weightings for Two rimes:

The whole Qualities / hiaher equal lower business ded

\begin{tabular}{l|ccccc} 
in the Check & & & \\
\hline $\begin{array}{l}\text { higher level } \\
\text { equal level }\end{array}$ & 1 & 3 & $1 / 3$ & 1 & 0.1998 \\
inual & $1 / 3$ & 1 & $1 / 5$ & $1 / 3$ & 0.0781
\end{tabular}


lower level

business dep

$$
\lambda_{\max }=4.0435
$$

13

3.5

5$$
C I=0.0145
$$

VI. The oriainal Treatment to the first data

We concern that sometimes the checking officers reach error scores' to their checked cadres. Meanwhile to avoid some cherking officers. likeness and prejudice; we make rhe first data original by the theory of error in surveyina. We'll qet rid of the great error.

1). The expected utility of the calculated single taraet.

$$
\bar{G}_{i}=\frac{1}{w} \sum_{j=1}^{N} G{ }_{j i}
$$

G -- the arithmetic mean of taraet $i$ ( including)

i

$G$ - the value of each point in target $i$ (the value of marks in ji targec)

$j$--- the lower target of the statistics of the checked officers $N$-- the number of the checked officers

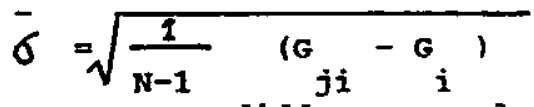

2). The average square root difference calculated through the formula:

$$
\sigma=\sqrt{\frac{1}{N-1}}\left(G_{j i}-G_{i}\right)
$$

3). The chauvent Test of the reliability of datum

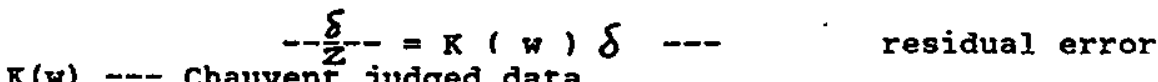

If $\delta, R(w), z, G$ should be get rid of, the above steps are repeated until the whole data are suitable for the chauvent judged data.

VII. The Device of Perfect AHP Used in the Computer soft-ware in the Checking and Evaluation of officers

To make the case of the army and of ofticers department easy, we have designed multi-functioned computer soft-wares.

The following drawing of the computer soft-wares is shown in Eigure 2 .

The soft-ware has powerful function of the conversation between person and machine. People who haven't got education in computer can also learn it quickly. Every step is marked by chinese characters. The checkina result may be shown in drawina. copy, and typewriting. The image is so audio-visual that it is easily analized, such as the showing of the rectandular drawing of the 
printed branch target of cadres' hierarchy curve. the rectanaular drawing of total scores. The sote-ware is dobular and easitv input. It may revise the taraet system. hierarchy constructure relative weighting and the contents of word storage. It may be used not only in the checking of leaders and also in the checkind of ordinary cadres It provides an assitant decision tool for the cadre department which chooses. deblovs. abpoints and dismisses cadres.

Addition. The research work was directed by Associate Professor Zhana Honasena ( Suber Enaineer) Director Wand Guizhona ( Suner Enaineer, and it is subdorted by the chief of cadre section in General. Staft Encineering Armv Li xincinn Denutv chief Ra Tinde and Zhand Jin. With sincere thanks. 